\title{
Newborn Care Practices of Mothers in a Rural Community in Baitadi, Nepal
}

\author{
Devkota MD \& Bhatta MR \\ Institute of Medicine, Maharajgunja Campus, Kathmandu, Nepal \\ madan.bhatta@gmail.com
}

\begin{abstract}
Background: Despite efforts by government and other agencies, neonatal morbidity and mortality are still high in Nepal. Among all other reasons, newborn care practices are one of the major contributors for such high rates of morbidity and mortality.
\end{abstract}

Objective: To find out the essential newborn care practices in a rural community.

Design: Community based descriptive (cross sectional) and explorative study.

Setting: Siddheshwar, Siddhapur and Gujar VDCs of Baitadi district.

Participants: 71 mothers having less than 3 month infants.

Materials and Methods: Semi-structured pre-tested tools were used to interview mothers along with check list for case studies.

Statistical analysis: Data was analyzed using SPSS 11.5 for widows.

Results and Conclusion: More than two third mothers $(71.8 \%)$ took ANC service and average number of ANC service was 3.16 times. Most of the deliveries (91.5\%) took place at home $(69.0 \%$ in living room and $22.5 \%$ in cattle shed) which were mostly conducted by relatives $(29.6 \%)$ or family members $(35.2 \%)$ or self $(8.5 \%)$. Nearly two third of the respondents $(64.8 \%)$ did not use clean home delivery kit (CHDK) and more than one fourth $(26.8 \%)$ used "used blade" for cord cutting. About $86.0 \%$ of the respondents did not use any substance on the stump, and one third (33.8\%) did not wipe their babies. Most of the respondents $(84.4 \%)$ burnt firewood for heating the room. More than two third $(38 \%)$ of the respondents bathed their babies within one hour and only $18.3 \%$ of respondents bathed their babies after 24 hours. Only $7.0 \%$ of the respondents' breast fed their babies within one hour, though all babies were breast fed. Nearly one third $(29.6 \%)$ of the respondents discarded the first milk (colostrum). Most of the respondents $(87.3 \%)$ did not give pre lacteals to their newborns and more than two third $(70.4 \%)$ did not seek any health services for their newborns. More than one third (35.2\%) did not vaccinate their babies. Regarding the birth preparedness practices more than half did not practice for each of pregnancy, delivery and newborn care. The common reasons behind harmful practices were lack of awareness, traditional cultural practices and lack of free time for the mothers. Therefore, there is an urgent need to introduce interventions to address newborn care practices focusing on marginalized and disadvantaged communities in the area.

Keywords: Newborn, Essential New Born Care, Institutional delivery, Birth preparedness package, ANC

\section{INTRODUCTION}

In Nepal infant and neonatal mortality rate is very high i.e. IMR is 48/1000 live births; NMR is 33/1000 live births and perinatal mortality rate (PMR) is $45 / 1000$ live births and still births. It is estimated that in Nepal nearly 50,000 children under one year of age die every twelve months. Infant mortality has declined by $41 \%$ over the 15 year period from 82 deaths per 1000 live births to 48. The corresponding decline in the neonatal mortality over the 15 year period is only $33 \% .^{12,6}$

Appropriate care for the normal newborn is neither widely understood nor practiced in the community or health system. Traditional attitudes and practices dominate newborn care and are often hazardous. Hypothermia has been shown to be an important cause of neonatal morbidity in hospital settings in Nepal. Neonatal danger signs are commonly not recognized, whilst harmless conditions often lead to unnecessary referral. ${ }^{12}$ For newborn infants in Nepal, perinatal illness usually begins and ends at home. The reasons for this are economic, geographical, and cultural and institutional. ${ }^{13}$ Birthing is considered a ritual process and often takes place in an animal shed, which is prepared for the delivery by having the floor plastered with a paste made of cow dung and locally available soil. The surface need for the delivery is either not covered or only scantly covered with straw, an old bed sheet, old sacks, or polyvinyl sheet. Traditional faith healers when called to attend a difficult birth do not go closer to the mother than the doorway of the shed. Women are considered semi untouchable when they are giving birth and must stay in a place apart from the rest of the family for 11-28 days after the baby is born. ${ }^{14}$ Studies from rural areas of Nepal showed 
that only $6 \%$ of home deliveries are attended by skilled government health workers and newborn care practices are unhygienic and high risk. ${ }^{15}$ Though it is claimed that overall newborn care practices are unsatisfactory, situation of rural places of Nepal has rarely been assessed. Regular health service data doesn't provide detailed picture of newborn situation of rural place. This paper reports the situation of essential newborn care practices in rural community of far western Nepal.

\section{METHODOLOGY}

\section{Procedure and participants}

This study was descriptive cross sectional study. After getting ethical approval for research proposal and tool from Institute of Medicine, Tribhuvan University, Nepal face to face oral interview was conducted with 71 participants from Baitadi district of Farwestern Nepal. The study site was chosen purposively to find the situation of newborn care status in a one of most rural areas of Nepal. There are 62 Village Development Committees (VDCs), one municipality, 13 Ilakas and 2 electoral constituencies. Study area included were three VDCs of Baitadi (Siddhapur, Siddheshwar and Gujar). These are typical rural VDCs of the district having similar socioeconomic and demographic characteristics. These VDCs lie in southern part of the district very near to the head quarter of Dadeldhura district. The population of the Siddhapur, Siddheshwar and Gujar VDCs according to the census 2001 was 2212(M-1070, F-1142), 4014(M-1969, F-2045) and 2759 (M-1324, F-1435) respectively. Each VDC has a sub health post (SHP). Bramin, Chetri, Thakuri, Kami, Damai and Lohar are the major caste and Hindu is the major religion. Most of the households depend upon the agriculture for living. Most of the active male population is out of the home especially in major cities of India for the search of job. Due to the poor educational status migrant male get the risky job like labor, guarding, laundryman, cook man etc with low salary. Seasonally they return to home with clothes and necessary goods for living along with cash for family expenditure. They returned to India after some time.

\section{Interview questionnaire}

Interview questionnaire was used for this study. The questionnaire was adopted from previous studies that had studied newborn health. Questionnaire for background variable and safe delivery kit (Clean Home Delivery Kit) was adopted from Maternal and Neonatal Health Survey Questionnaire of Johns Hopkins's University conducted on 2002 in Nepal (Johns Hopkins Bloomberg School of Public Health Center for Communication Programs, 2002). Other newborn questions were adopted from Nepal Demographic and Health Survey 2006 (Ministry of Health and Population (MOHP) [Nepal], New ERA, \& Macro International Inc, 2007). The draft questionnaire was then reviewed Institute of Medicine. Then the tool was pretested. Before pretesting, two interviewers were trained on training skills. Both of the interviewers held Community Medical Auxiliary Trainings and trained by principle investigator. Then pretesting was done in the similar settings of Baitadi district. Necessary changes were done in religion questionnaire, caste, reasons for not wiping babies. Feedback was provided to the interviewers by the principle investigator.

\section{STATISTICAL ANALYSIS}

Collected data were for checked for errors by principle investigator. Then the data was coded and entered for analysed by using Statistical Package for Social Sciences (SPSS-13). Descriptive statistics was analysed by describing in frequency distribution and cross tabulation.

\section{FINDINGS, DISCUSSION \& CONCLUSION}

Newborn health care starts long before birth, it starts with caring for pregnant mothers. During pregnancy a mother needs to be adequately nourished, from infections and monitored for complications. During labor and delivery, emergency obstetric care is particularly critical to life threatening complications. Good care during pregnancy, labor and birth is the first step in good newborn care. At birth the newborn must adopt quickly outside the uterus. Newborn's body must make many changes which begin at birth and continue throughout the newborn period. The first and the most important change are to start breathing. Other changes are regulating the body temperature, feeding and developing the ability to fight infections (immune system). The first week and month of the newborn's life are a time of risk. More than half of all newborn deaths happen in the first seven days and although the risk of death decreases as time passes, every newborn needs careful attention during the first month of life. ${ }^{4}$

\section{Socio demog raphic characteristics of the respondents}

This study was carried out in a rural community of Baitadi district of Nepal. Almost all the houses were headed by the male member of the family. Joint family system was found predominant $(64.8 \%)$, literacy level of mothers was very low $(46.5 \%)$ and agriculture was the major occupation (91.5\%) of mothers. Most of the respondents (62.0\%) belonged to the age group 20 to 30 years. Median age of the respondents was 24 years. All the respondents were Hindu and there was dominance of joint family (64.8\%).Regarding ethnicity $43.7 \%$ were chhetry, $46.5 \%$ were Brahmin and $9.9 \%$ were from lower caste. Major source of income was labor (husbands were engaged in labor) and annual sustainability from the income was only in $36.6 \%$ of the respondents. Median age of the respondents when first baby was born was 19 years. Some $(11.3 \%)$ of respondents were suffered from five or more birth order (first, second and third birth order mostly). More than half of the respondents $(59.2 \%)$ respondents gave birth of male child as the last birth. 


\section{Newborn care practices of mothers before birth}

ANC is more beneficial in preventing adverse pregnancy outcomes when it is sought early in the pregnancy and continued through delivery. The WHO recommends that a woman without complications have at least four ANC visits to provide sufficient ANC. Twenty eight percent of mothers received no ANC which was similar to the previous study $i$. e. $26.0 \% .^{6}$ The practice of ANC in mothers of lower caste was poor $(28.6 \%)$ which may be due to the poor knowledge regarding ANC services in comparison to the chhetry (90.3\%). Use of ANC services was also found strongly related to the mother's level of education. Mothers with higher secondary level education received hundred percent ANC service in comparison to the illiterate mothers (63.2\%). Similarly mothers with less than 20 years received more ANC service (77.8\%) in comparison to the mothers more than 30 years $(60.0 \%)$. Average time of ANC visits was found 3.16 times which was better than the previous findings i.e. 2.3 times ${ }^{16}$ with SD 1.046. Mostly ANC services were received from SHP and MCHWs were the main service provider. Though ANC services provided by the MCHWs were satisfactory quantitatively, the qualitative part of the service was poor as $74.5 \%$ of the clients did not get any type of counseling service. The most common reasons for not receiving the ANC services were "due to work" and "don't know".

TT injections are given during pregnancy for the prevention of neonatal tetanus, a major cause of death among infants. For full protection a pregnant woman should receive at least two doses during each pregnancy. Five doses are considered to provide life time protection. Nearly $75 \%$ of mothers received TT vaccine which was similar to the previous finding. ${ }^{6}$ The practice of TT vaccination was poor in the mothers of lower caste $(42.9 \%)$ in comparison to the chhetry $(83.9 \%)$. Similarly mothers from nuclear family were found less likely receiving TT vaccine $(64.0 \%)$ in comparison to the joint family $(80.4 \%)$ which may be due to the lack of leisure time. Similarly age and education status of the mothers also influenced the practice of TT. Average time of receiving TT vaccine was 2.3 times with SD 0.668. The commonest reasons for not receiving the TT vaccine were "don't know", "due to lack of leisure time" and "cultural cause".

\section{Newborn Care practices of mothers at Birth}

Obstetric care from a trained provider during delivery is recognized as critical for the reduction of maternal and neonatal mortality. Most of the mothers were assisted during delivery by family members and relatives $(63.8 \%)$ and $8.5 \%$ were delivered without any help which is similar to the previous studies. ${ }^{6,7}$

Proper medical attention and hygienic conditions during delivery can reduce the risk of complications and infections that may cause the death or serious illness of the mother and the baby or both. The proportion of home births $(91.5 \%)$ in this study was higher than that of previous findings ${ }^{6,7}$. Again 22.5\% of the deliveries took place in cattle shed which signifies the hygiene and care practices at birth in the rural areas of far western Nepal. The practice was found dependent with the caste, economic status and education of the respondents. Nearly all the respondents who were illiterate $(97.4 \%)$ gave birth at home with $31.6 \%$ in cattle shed.

Infection may account for up to $40.0 \%$ of neonatal mortality. ${ }^{25}$ Particular concerns at birth are a clean place, a clean surface, cleanliness of the hands of the attendants, clean cord tying, cutting and dressing and clean and dry wrapping of the baby. Nearly two thirds of the mothers (64.8\%) did not use CHDK which is a slightly improved figure in comparison to the previous studies. ${ }^{6}{ }^{7}$ The practice was associated with the caste, education, economic status and occupation of the mothers. The most common reason given beyond not using the CHDK was "don't know" which highlights the lack of knowledge among the respondents regarding $\mathrm{CHDK}$.

Proper practice of cutting the umbilical cord is one of the primary care of the newborn. Nearly two third of the respondents $(67.6 \%)$ used "new/boiled blade" to cut the cord but still $26.8 \%$ of the respondents cut the cord with "used blade" which is discouraging figure in comparison to the previous findings. ${ }^{6,19}$ The associated factors with it were caste, education and age of the mother. Half (50\%) of the mothers of age more than 30 years used " used blade" for the cord cutting in comparison to the mothers under 20 years $(22.2 \%)$. Similarly, most of the mothers from lower caste $(85.7 \%)$ used "used blade" in comparison to the mothers from Brahmin and chhetry family $(21.2 \%$ and $19.4 \%$ respectively).

It is encouraging that $85.9 \%$ of the mothers did not apply anything on the stump, a higher percentage than previous studies. $^{7,19}$

\section{Newborn Care Practices of mothers after Birth}

Though this study revealed that about two third of the babies were wiped and all of the babies were wrapped, the proper time of wrapping and materials used for wiping were unclear and suspecting. Most of the mothers from lower caste $(85.7 \%)$ did not wipe their babies in comparison to Brahmin (39.4\%) and chhetry (16.1\%) mothers. Most of the mothers who did not practice wiping $(83.3 \%)$ did not know about the wiping and its importance. The materials used for wrapping the baby were mostly unhygienic and thin pieces which may not be sufficient to warm the baby. Regarding the practices of warming the room firewood burning was common but the effects of indoor air pollution to mother and babies are the matters of concerns. About one fourth of the mothers closed the window with firewood burning to maintain the warm of the room but they were unaware about the effects of indoor air pollution. 
In most of the cases $(81.7 \%)$ practice of bathing was done within 24 hours. Thirty eight percent of the mothers bathed their babies within one hour which is improved figure in comparison to the previous finding. ${ }^{6,19}$ The associated factors with it were caste, occupation, age of the respondents, and sex and order of the child. The practice of bathing male child earlier than the female child was higher i.e. nearly half $(47.6 \%)$ of the male child were bathed within one hour in comparison to the female child (24.1\%).

All women breastfed their infants. Most of the newborns $(87.3 \%)$ were given breast milk as the first feed which is encouraging as compared to previous studies $32.9 \%{ }^{19}$ and $63 \% .{ }^{6}$ Only $7 \%$ of mothers breastfed their babies within one hour which is discouraging in comparison to the previous study i.e. $35 \% .{ }^{6}$ Age of the mother and sex of the child were associated factors regarding the practice. Nearly one fourth $(24.1 \%)$ of the respondents did not give first milk to their babies and most of them answered "don't know" and "culture" for the reasons of not practicing it. Caste and sex of the child were the related factors for practicing colostrum feeding. More female babies were given colustrum (75.9\%) in comparison to the male babies $(66.7 \%)$ which may be due to the higher importance given to the male babies thinking that colustrum may harm the baby which is the existing culture in the rural areas. Mostly given pre lacteal was cow's or buffalo's milk.

Average number of times of breast feeding at night between sunset and sun rise was 3.14 times and SD was 1.138. Similarly average number of times of breast feeding during day time was 5.10 times and SD was 1.742 . This denotes that frequency of breast feeding is not satisfactory in the rural areas of Nepal which may be due to the lack of leisure time and lack of understanding about the importance of breast feeding among the typical rural women.

Most of the mothers $(70.4 \%)$ did not seek health services for their newborn. The frequently repeated answers for the cause of this were "due to lack of leisure time", "healthy baby" and "don't know". Of them who received services most got services from MCHWs (57.1\%) and ANM (28.6\%). Average time seeking the health service after the birth of baby was 12.86 days and SD was very high (10.145).

This study has identified important information about newborn care practices in rural Nepal. In spite of the fact that most of the respondents were economically deprived, illiterate and unreached from modern medical facilities; harmful newborn care practices were common. As most of the deliveries took place at home, attendants at delivery were mostly unskilled, use of CHDK was very low, cord cutting practices were still unhygienic, thermal control measures were lacking as well as inappropriate, prevailing unhealthy breast feeding practices, lacking in immunization practices and birth preparedness practices were also poor; need of intervention program is obvious. Mostly caste system of the society and education level of the mothers was the hindering factors including negative cultural practices for the appropriate newborn care practices.

For the prevailing practices, intervention should be focused towards the selective approach rather than prevailing blanket approach i.e. those factions of the society which are devoid of relevant knowledge and practice like suppressed and unreached communities should be prioritized first incase of intervention program. As counseling services provided by the health workers were of poor quality and inadequate, the prevailing unhealthy practices in the area should be discussed with the health care providers and communication strategies through mass media and inter personal education during antenatal visits may be studied for their effectiveness. Unhealthy practices of newborn care can also be discussed with family members and relatives including key players in the society so that they take special action in preventing these harmful practices. There is an urgent need to educate mothers or responsible family members especially mothers in-law in the newborn care practices on early neonatal care.

The roles of community actors such as mothers in - law, husbands, local healers and private medical practitioners, and increased access to properly trained FCHV/TBA need to be addressed if birth preparedness practices and newborn care practices are to be improved and delays in reaching health facilities are to be shortened. The information identified during the study will assist in planning health interventions to change behavior.

\section{REFERENCES}

1. Department of reproductive health and research, family and community health, WHO, Geneva. Research on reproductive health at WHO,biannual report, 20002001.

2 Save the Children. Saving Millions of Newborn Lives Within Reach. www.savethechildern.org.htm

3. Landmark research on newborn survival. The Lancet. BMJ March 3, 2005.

4. Beck D, Ganges F, Goldman S, et. al. The State of the World's Newborns. A Report from Saving Newborn Lives. Washington, DC; 2001.

5. Save the Children Federation. Saving Newborn Lives. www.savethechildern.org.htm

6. MoH, Government of Nepal/ New Era/ORC Macro, 2006. Nepal Demographic and Health Survey, Kathmandu, 2006.

7. Osrin D, Tumbahangphe KM, Shrestha D, Mesko N, Shrestha BP, Manandhar MK, et. al. Cross sectional, community based study of care of newborn infants in Nepal. BMJ 2002; 325:1063. 
8. Save the children in partnership with the center for development and population activities (CEDPA). Baseline survey report on Birth Preparedness, Siraha district, Nepal; 2002.

9. Department of reproductive health and research, family and community health, WHO, Geneva. Integrated management of pregnancy, child birth, post partum and new born care: A guide for essential care practices; 2003.

10. Devkota MD. Community management of sick neonates in Kailali districts: a study. Department of community medicine and family health, Institute of medicine, Tribhuvan University, Kathmandu, Nepal, 2004.

11. London School of Hygiene \& Tropical Medicine at Senate House, Malet Street. Urgent call to save lives of 30 million under fives over next decade.htm (Tracking Progress in Child Survival: Countdown to 2015; London, December 13-14 2005).

12. Family health division, DoHS, MoHP, Nepal Government, National Neonatal Health Strategy, 2004.

13. Mesko N, Osrin D, Tamang S, Shrestha BP , Manandhar DS , Manandhar M, et. al. Care for perinatal illness in rural Nepal: a descriptive study with cross-sectional and qualitative components. BMC International Health and Human Rights 2003, 3:3 doi: 10.1186/1472-698X-3-3.

14. Save the children: saving newborn lives. State of the world's newborns: Nepal, July 2002.

15. Sreeramareddy CR, joshi HS, Sreekumaran B.V. Giri S, Chuni N. Home delivery and newborn care practices among urban women in western Nepal: a questionnaire survey. Department of comm. Med. Manipal College of medical sciences, pokhara, Nepal.

16. DoHS, MoHP, Government of Nepal. Annual report, 2005/2006.

17. SCF Himalayan field office, Katmandu, Nepal. Formative research on newborn care practices in the communities of Kailali, Sep 2002.

18. Nepalese women need educating about care of newborns; BMJ. 2002 November 9; 325(7372): 0.

19. Rahi M, Taneja DK, Misra A, Mathur NB, Badhan S. Care practices in an urban slum of Delhi. Department of Community Medicine, Maulana Azad Medical College. Newborn - 110 002, India; Department of Pediatrics, Maulana Azad Medical College - 110002 , India; Year: 2006; Volume: 60; Issue: 12; Page: 506513.

20. Thapa N, Chongsuvivatwong V. Alan F. High risk childbirth practices in remote Nepal and their determinants. Women and Health: a multi disciplinary journal of women's health issues. Vol. 31; Issue 4.

21. Beun MH, Wood SK. Acceptability and use of clean home delivery kits in Nepal: a qualitative study. J Health Popul Nutr. 2003 Dec; 21(4):367-73.

22. Fikree RF, Ali TS, Durocher J M and Rahbar M H. Newborn care practices in low socioeconomic settlements of Karachi, Pakistan. Social Science \& Medicine March 2005; Volume 60, Issue 5, Pages 911921.

23. Baqui AH, Williams EK, Darmstadt G L, Kumar V, Kiran TU, Panwar D. Newborn care in rural Uttar Pradesh. Journal of Midwifery \& Women's Health; Journal: Indian.

24. Save the children in partnership with DPHO, Kailali: Baseline survey report on savings newborns lives in 18 VDCs and 1 Municipality of Kailali; May 2003.

25. Bang A, Bang R, Baitule S, Deshmukh M, Reddy M .Burden of morbidities and unmet need for health care in rural neonates- a prospective observational study in Gadchi roli , India, Indian pediatric journal 2001,38:952-965.

Health Prospect 2011, Vol. 10 